$$
\text { العلامات و اللوحات الإرشادية }
$$

و دور ها في نشر الو عي وتأمين بيئة العل في المستشفيات و المراكز الطبية

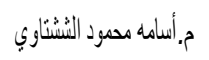

إستثناري السلامة و الصحة المهنية وتامين بيئة العمل

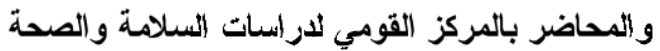

المهنية وتأمين بيئة العمل ( NIOS)- مصرئ لافرات

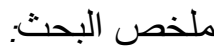

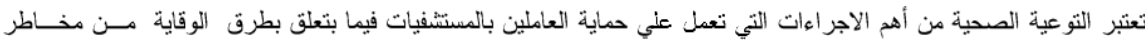

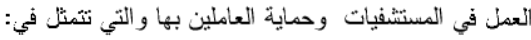

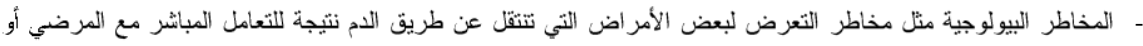

مع المخلفات الطبية الخطرة .

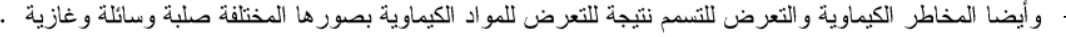

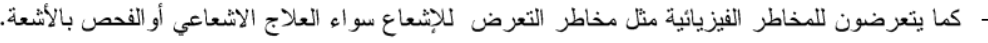

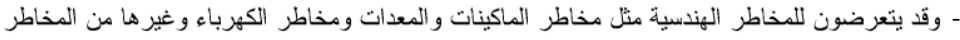

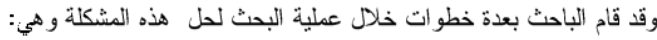

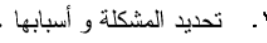

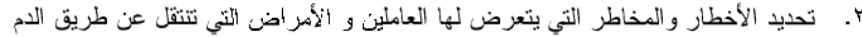

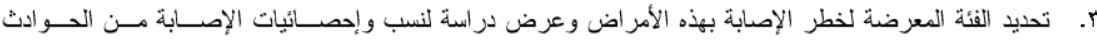

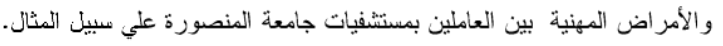

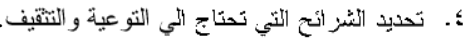

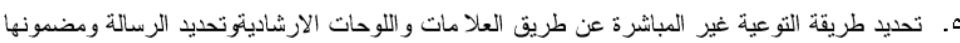

7. . عرض بعض النماذج من اللوحات قام الباحث بتصميمها بنفسه وتوضيح مدلولها.

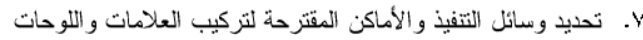

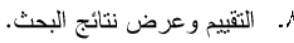

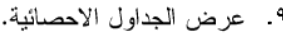

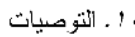

بالوقاية ومكافحة العدوي وحماية العاملين في

المقامة:

المستشفيات ومر اكز الر عاية الصـــية مــن

إنصب اهتمام المتخصصبن علي المستوبين

الأخطار الموجودة من حولهم في بيئة العمل.

التعالمي و المحلي في الآونــة الأخيــرة فـــي

نشأ هذا الاهنمام نتيجة لو جود مجمو عة مــن

مجالي الرعاية الطبية

الظروف التي طر أَ على عالمنا المعاصــر

و السلامة و الصحة المهنيــة وتـــأمين بيئـــة

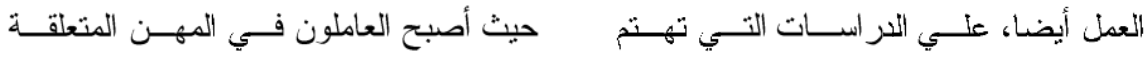


إهدارا صارخا للطاقة البشرية التي يجـب

الحفاظ عليها.

كما ظهر أيضا الدور غير المباشر والمــؤثر

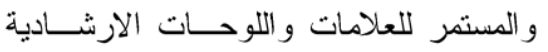

للوقابة و التحذير و المنع و التذكير بالأخطـار

و المخاطر الموجودة في بيئة العمل و التي تم

تطوير ها وتعديلها بالتعاون بين إدارة السلامة

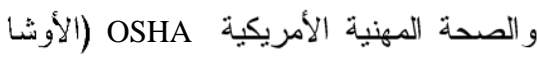

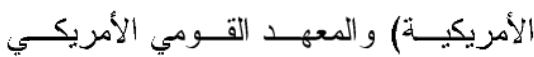

للمو أصفات (ANSI) عام ؛ ا. r.

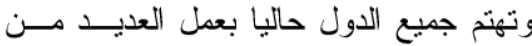

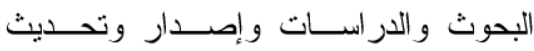

القو انين و التشريعات التي تسعي من خلالهــا

إلي منع أو الحد مــن احســـو ادث المســبية

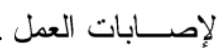

وقد اهتمت الدول الصناعية الكبري بحمايسـة

العامل وتأمين سلامته وظهر شعار " السلاهة

أو لا بدلا من الانتاج أو لاً.

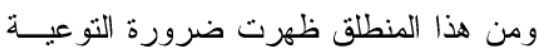

المباشرة بمخاطر العمل المختلفة عن طريق

المحاضــــر ات و التـــــريب و المطبو عــــات

و البر امج الاعلامية الموجهة.

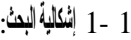

الإصـابات الخطيرة و الأمر اض المهنية التــي لقالي

تتجم عن تعرض بعض العاملين لحو ادث العمل

قد بلغ في مصر ( طبقا للجهاز المركزي للتنعيئة
بالمجالات الطبية ومنشآت الرعاية الصــحية هدفا للعدوي وللأخطار المحيطة بهر في بيئة العمل، الأمر الذي اســتلزم البحــث وزيـــادة

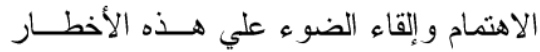

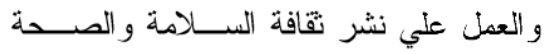

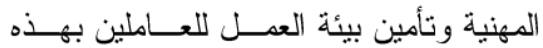

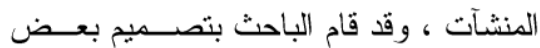
العلامات الارشادية لنقوم بدور ها في التوبة عية

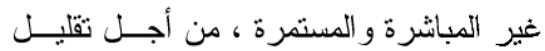
تعرضهم أو الحد من نتائج هذه المخاطر .

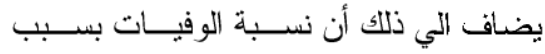

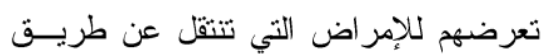

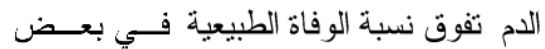

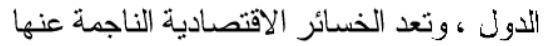

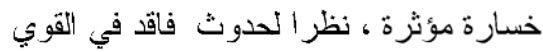
البشرية الددربة ذات الخبرة ، فكم من اسرة

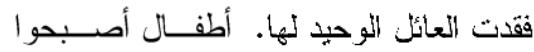

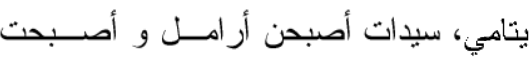

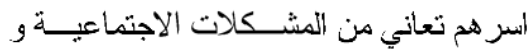
الإقتصادية الخطيرة. وبحسب إحصاءات منظمة العهـل الدوليـــة

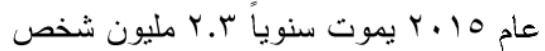

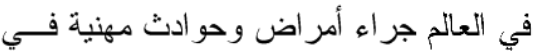

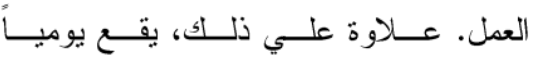

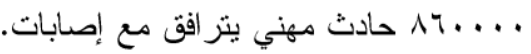

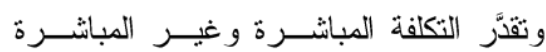

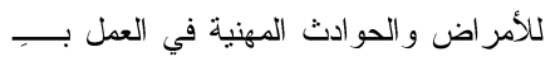

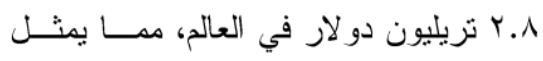




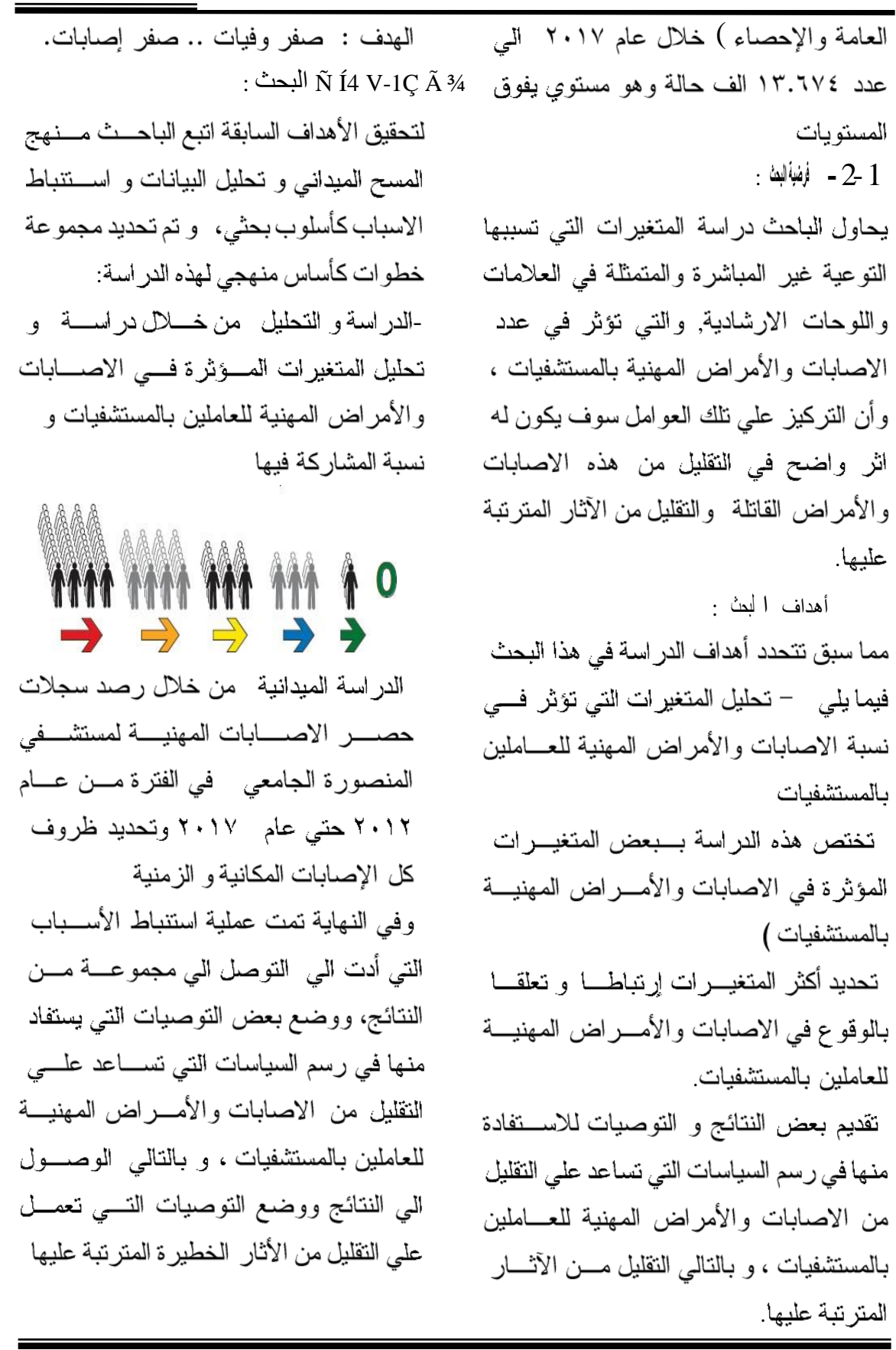


القوة البشرية بجامعة المنصورة ، حيث بيلغ عدد العاملين بالمستشفي هـ هب به و والمؤقتين 1 1 إ بالإضافة الي اعضاء هيئة التدريس باليس

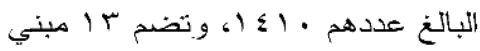
وتحتوبي علي r rol سريرا. 3 ـهناك مجمو عة من العو امل التي تثـارك معا في حدوث الاصدابات و الأمر اض المهنية ، و يمكن تقسيمها من حبــث العامـلـل البشــري

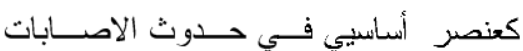
و الأمر اض المهنية ، ثم دور عملية التوعيـة الصحية ويلي ذلك خصـــائص بيئــة العمـلـل المكانبة ووقت حدوث الاصنابة ، ثم تعليمات و إجر اءات السلامة المطلوب اتباعها لتجنـبـب هذه الأخطار ، و سوف نتعرض فيمـــا يلــي لفاعلية كل عنصر من و اقع معطيات الدر اسة الميدانية للبحث. - 3 - 1 (الانسان ) العامل البشري كعنصــر حاضر و أساسي في الاصـابات و الأمــر اض المهنية. من الو اضح أن الإنسان يلعب دور ا أساسيا في

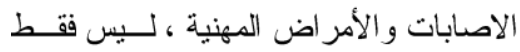

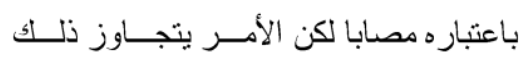
باعثباره أنه الأبي بيتولي متابعــة العناصــر الأخري كالسوائل المتخلفـة عـن أجســام المرضي و المصابين ، و الجو انب الأخــري التي تتم في نطاقها إدارة المخلفــات الطبيــة

$$
\text { إجر اءات القيد و البحث- }
$$$$
2 \text { - } 1 \text { - } 1 \text { جو انب البحث: }
$$

اشتثلت الدارسة علي المتغيرات المؤثرة فــي الأمراض و الإصـابات المهنية في بيئة العمل بين العاملين بمسنشفي المنصورة الجامعي المات تختص هذه الدر اسة بالعلامــات و اللوحـــات الارشادية و دورها في نشر الوعي وتـــأمين

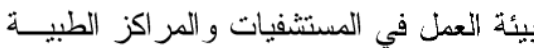
(الاننسان - التو عية - السلامة).

$$
\text { نصمير أدوات البعث: }
$$

قام الباحث بتصميم عـدد مــن العلامــات الارشادية المتخصصة ونوزيعها علي بعض المستشفيات لاستخدامها في عملية التوعيـة غير المباشرة للعاملين بعدة ألــــوان مختلفــة طبقا لمو اصفات إدارة الســلامة والصــــة

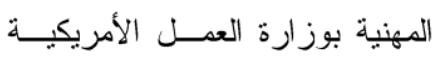

و التي قام بتصميمها المعهد الأمريكي القومي
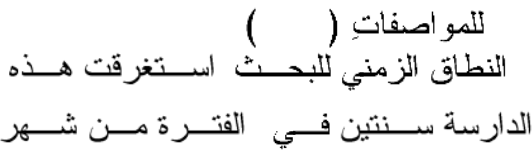

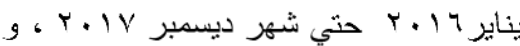
تنو عت فيها الإصـابات و الأمر اض المهنيــة من إصـابات خفيفة إلي إصابات بليغة

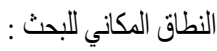

نم اخنيار مسنثفي المنصورة الجامعي ) كنطاق مكاني للبحث نظر الانها تمنل ثلث 


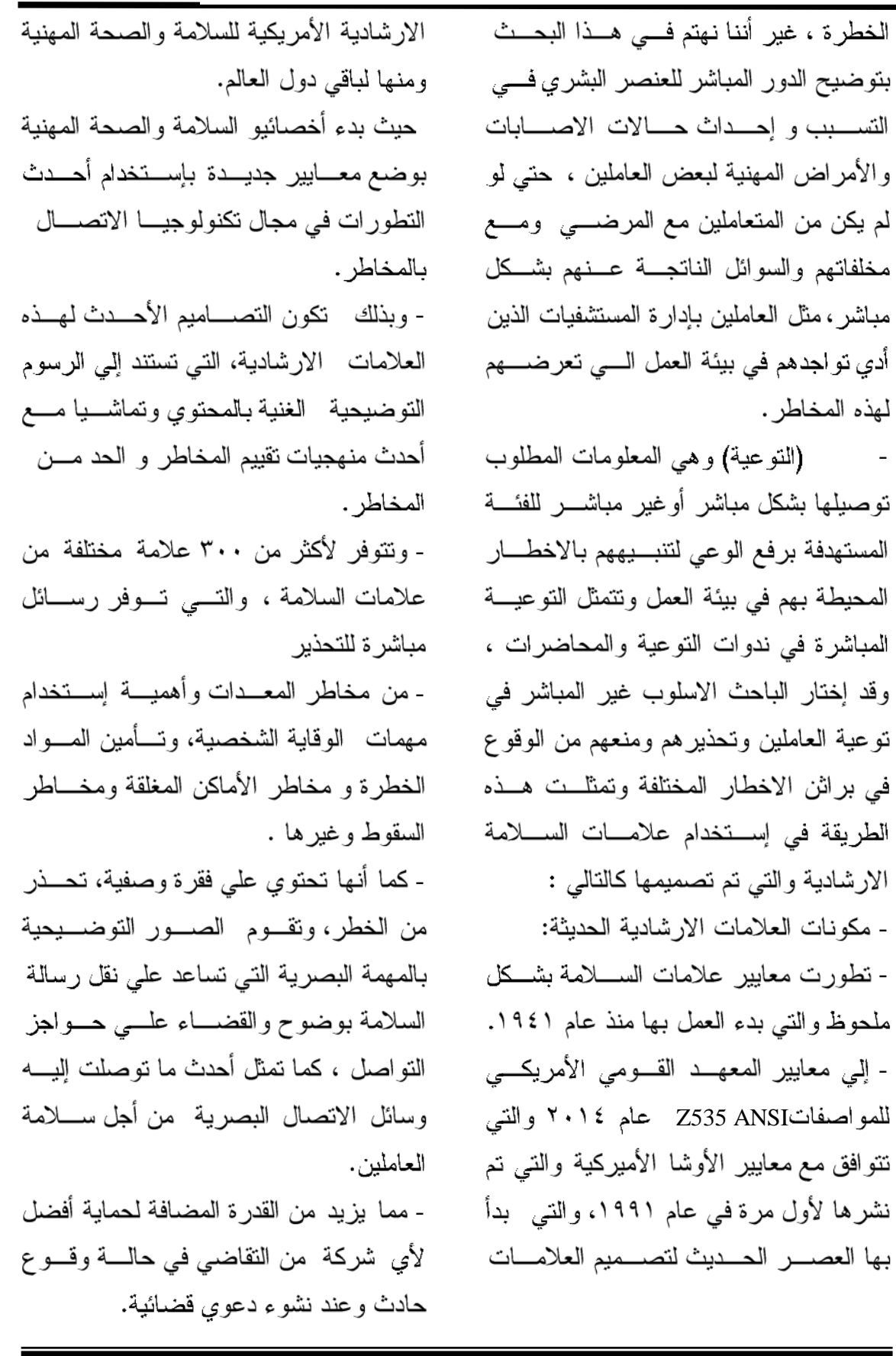


:Caution

\section{$\triangle$ CAUTION}

وتثير إلي موقف خطير، إذا لم يتم تجنبـه،

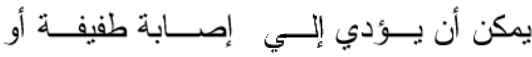

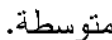

1- الكلمات الرمزية لرسائل السلامة التـي تحمل الثتبيه:

: Signal Words for Non-Hazard Alerting

Safety Messages

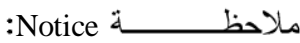

\section{NOTICE}

وتثير إلتي المعلومات التي تعتبــر مهمــة

ولكنها ليست ذات صلة مباشرة بالمخاطر

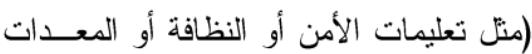
أو أضرار الممتلكات).

r- الكلمات الرمزية التعليمية لرســائل

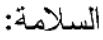

Signal Words for Instructional Safety Messages

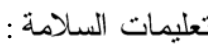

SAFETY INSTRUCTIONS

:Safety first (الســلامة أو لا)

\section{SAFETY FIRST}

هي كلمــة الإثـــارة المســتخدمة لتــوفير

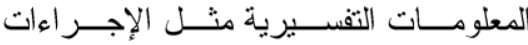

و التعليمات. كما بمكن أن تكـــون الكلمــات

الإشارية المستخدمة في هذه اللوحة الأكثــر

تحديدا. (علي سبيل المثال إجر اءات الغلــق
- مما يعطي المصداقية الكاملــة لإســتخدام

أحدث التكنولوجيات المستخدمة في تصــميم

العلامات الارشادية.

- المكونات الحديثة للعلامات الارشادية:

ا كرمز السلامة للتحذير Safety Alert Symbol :

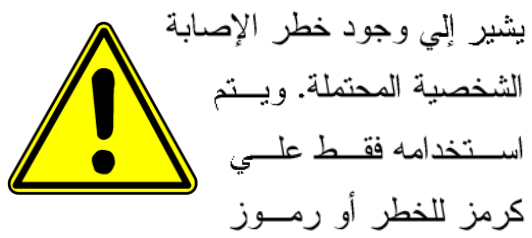

التحذير وهي من رموز التتبؤ بالخطر.

2

Signal Words for Hazard Alerting Safety

: Messages

خط :Danger

\section{DANGER}

وتثير إلتي حالة خطرة، إذا لم بتم تجنبهــا،

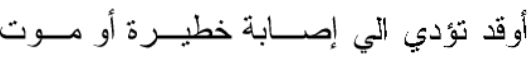

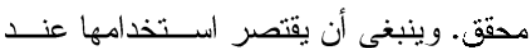
الحد الأقصي للخطر.

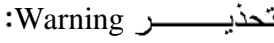

\section{$\triangle$ WARNING}

يثير إلي موقف خطير ، إذا لم يـتّم تجنبـهـ،

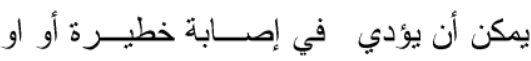

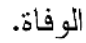




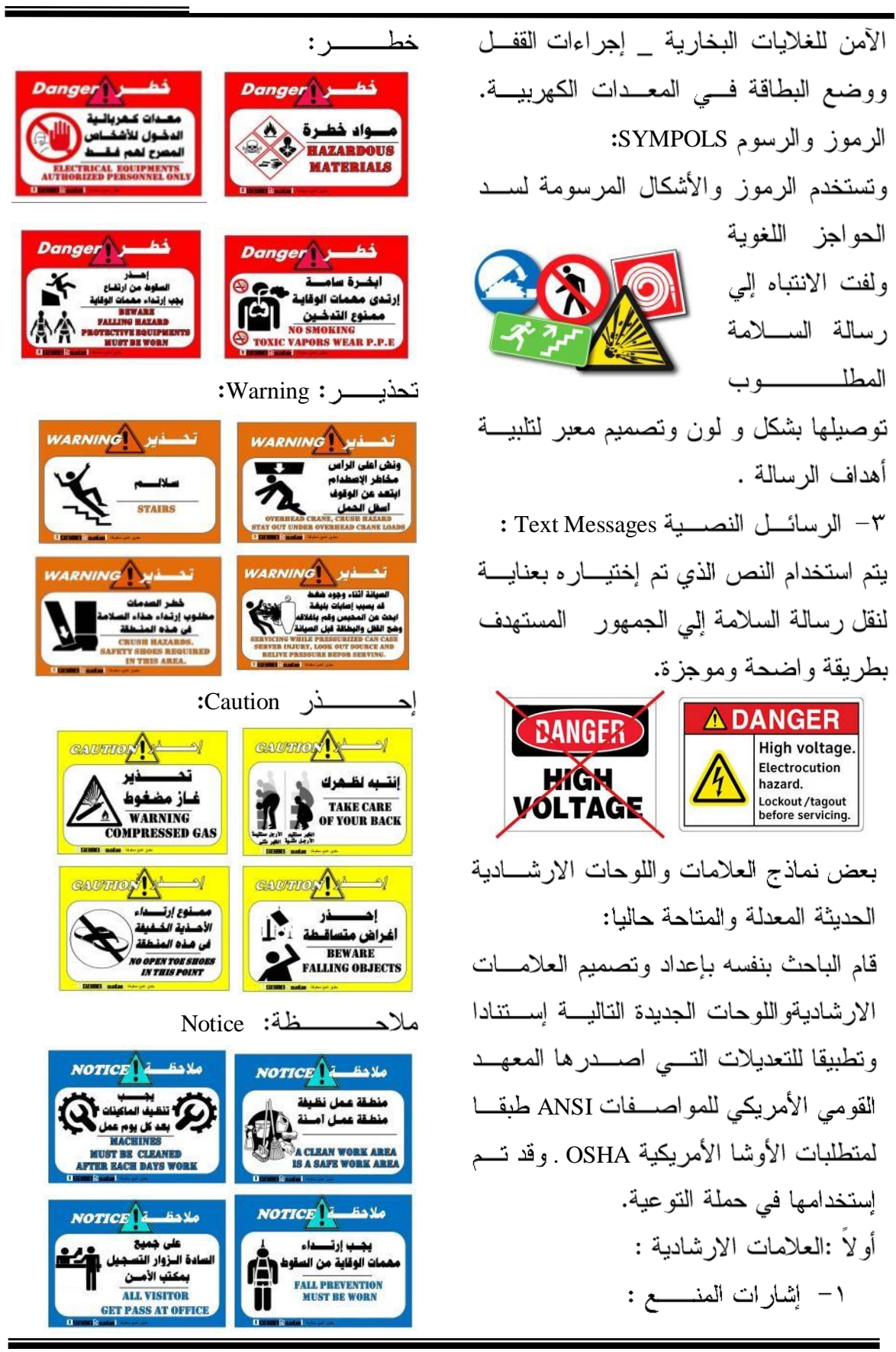




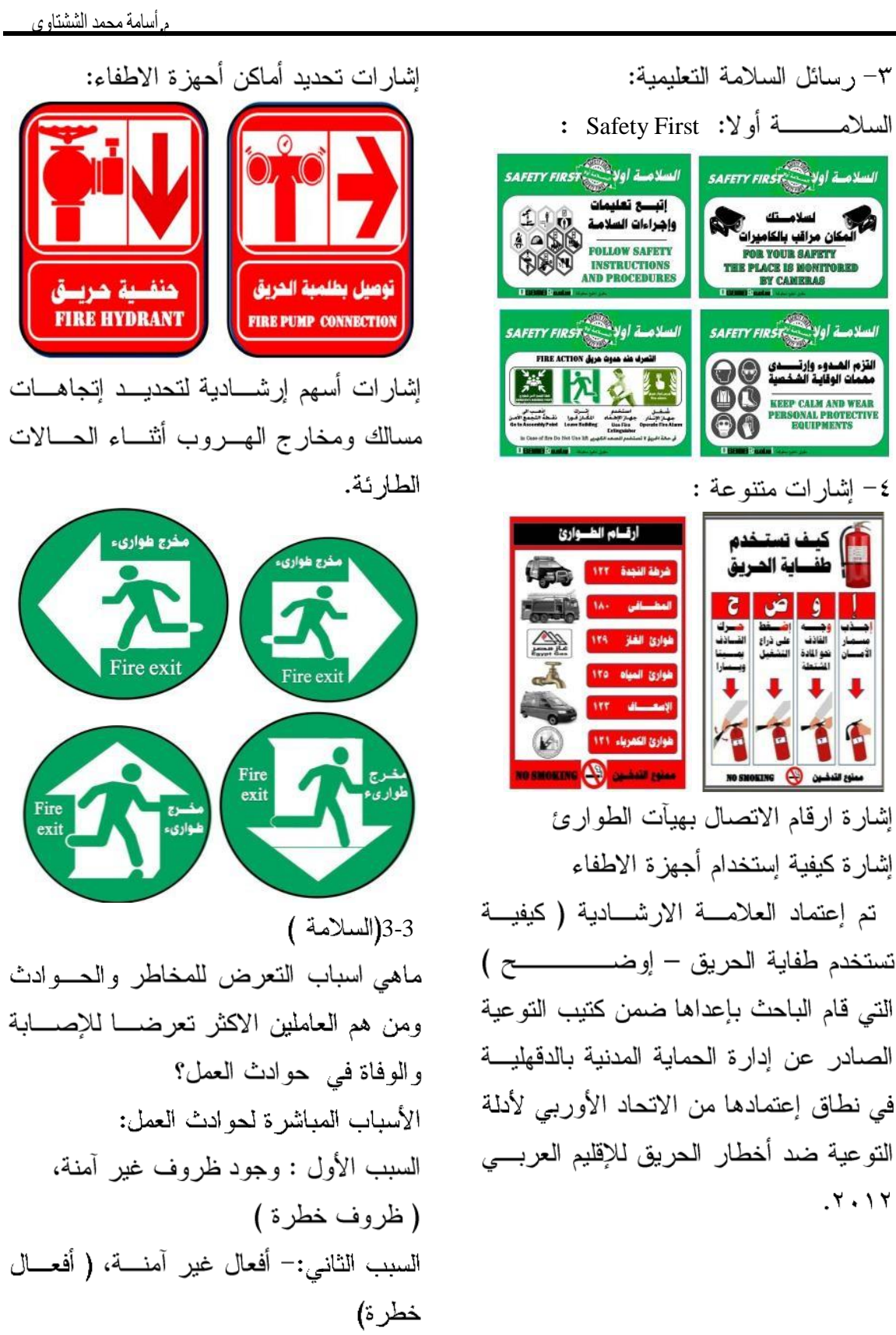


التمريض و العــاملين وتوضــبح المخــاطر

الناتجة عن أخطار العمل بشكل مستمر . تطبيث القو انين وتحديثها، حيث يجب الابلاغ عن الاصـابات الي الجهات المعنية لاتخــاذ اجر اءات وقائية.

ووجوب الاقرار بوجود أخطاء وأخطار في

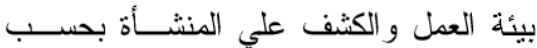
الحالة للتأكد من صداحية المعدات والالتزام بالمعاييز و التحقيق في حادث معين، و التأكد

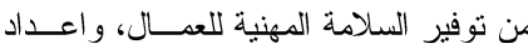
تقرير برفع للجهات المعنية لاتخاذ التــدابير المناسبة. - من هم الاكثر تعرضا للإصابة و الوفاة في حو ادث العمل؟ لا يقتصر حدوث الاصـــابات و الأمــر اض المهنية في مجالات العمل بالمسنثفيات ودور الرعاية الصحية فقط، بل ثمثل الــي بيـآت العمل الاخري وتتـــمل جميـع القطاعــات الاقتصادية ســـو اء الصـــناعية أو الزر اعيــة أؤ السياحة و التجارة و الخــدمات و الأعمـــال الادارية وغير ذلك. وفي كل موقعو وتنقسم الي أخطار محتملة واخري مفاجئة ، فالعامل في المصنع بتعرض لأخطار مبكانيكية فـي التعامل مع أجهزة ومعدات مختلفة، ولضجيج الآلات و المحركات، وللارتجاج الناجم عـن تشغيل بعض المعــدات، و لأجـــو اء داخليــة موبو عة نتيجة سوء التهوئة وتلـــوث الهـــو اء

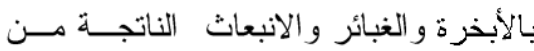

المهنية و هناك نتائج غير مباشرة ذات طابع اقتصادي أو مالي. و تظهر الخسائر الماديــة التـي تثكبـــها المنشاة او الدولة بشكل عام نتيجة حــــادث العمل و الإصابات و الأمر اض المهنية التـي تتتج عن ظروف بيئة العمل غيـر الآمنــة، ويظهر ذلك في أبام العمل الضـــائعة بســـبـ إصابات العمل و الأمر اض المهنية وبالإضـافة إلبي النتائج السلبية المثرثبة عن عدم كفايـة إجر اءات السلامة و الصــــة المهنيــة فــي المنشأة والتي نظهر آثار ها علي العمال. و. أيضا زيادة خطورة العمل كلمــا كانــــ إمكانية إصـابة الفــرد بحادثة العمل أكبــر، و هذا أيضـــا أمسـر منطقـي وموضـــوعي، فظروف العمل الخطرة وغير الآمنــة تتــيح الفرصة بشكل كبير لإمكانية تعرض العامل

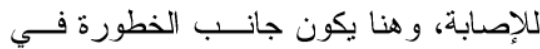
غالب الأحيان خارج عن إر ادة العامل نفسه، و غير قادر علي تجنبه فـــي كثبــر مــن الأحيان.

وييقي الجانب المهه وهو التنقيف و التثوعيـة المستمر علي كافة المستويات :

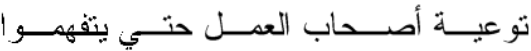
مسؤولياتهم.

وتوعية العمال حتي يعرفو ا حقوقهم وكيفيـة

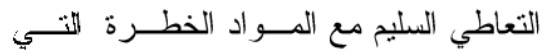

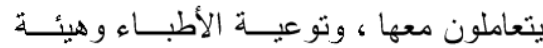




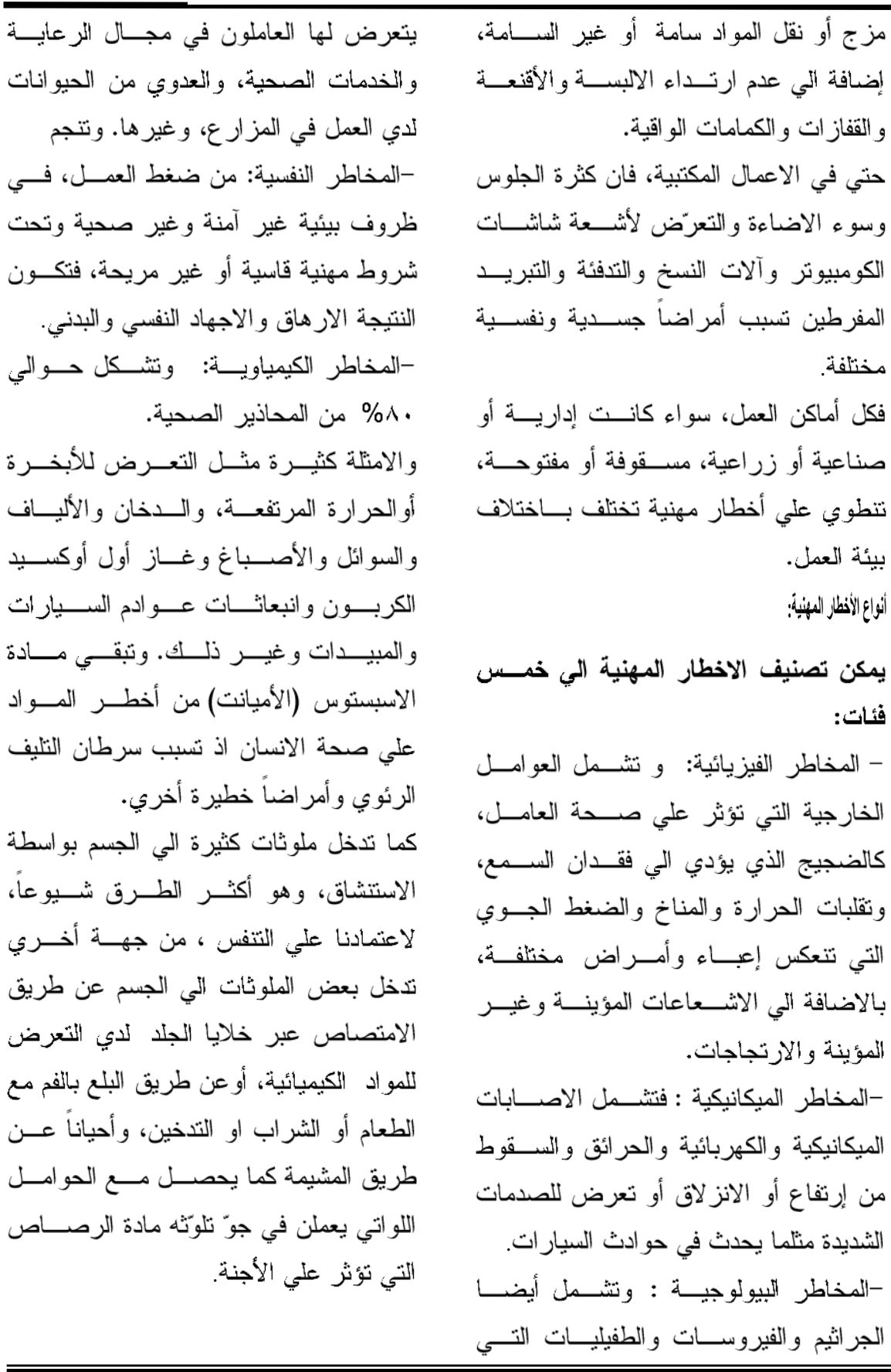


إحصاؤها ، لكن الامر اض المهنية مــا زال

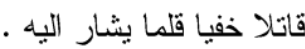
وبصفة عامة يكون العمــال صــغار الســن العـن

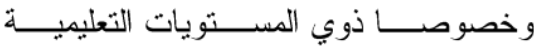
المنخفضة هم الفئة الأكثر تعرضا للحــو ادث

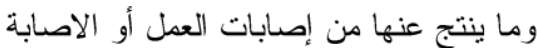

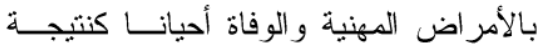
حتمية للجهل وقلة الوعي وهم الفئة الأكثـر

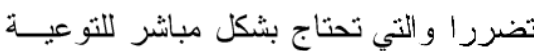

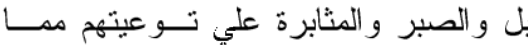
يصب في صالح المجتمع بــل و الاقتصـــاد القومي بثكل كامل.

وبعد توزيع العلامسـات الارشـادية بأقسـام

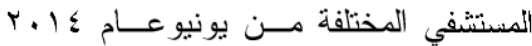

للعاملنين في المناطق ذات النصبي الاكبر من

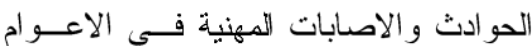
السابقة و هم : - - العاملون بأقسام الاشعة - الـــورش ومحطات الديزل - اقســام الاثتـعة الاتعة العلاجية - وحدة الكوبلت و المعـادل

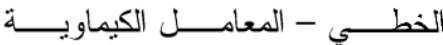

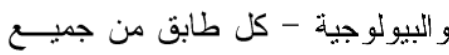
طو ابق مباني المستشفي - العساملين بصيانة الصرف الصحي - العنايــة المركزة - العمليات و العقيم المركزي لهي - المطابخ - المغاسل - المخازن الرئيســية ومخازن الادوية . - الممرات الرئيسية.
وتتوع طرق الوقاية بتتوع الاخطار التـي

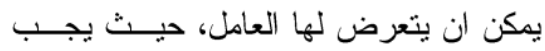

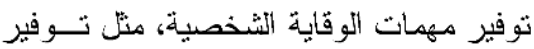
الكمامات التي تمنع استتشاق الغبار و الغازات

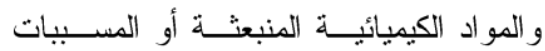

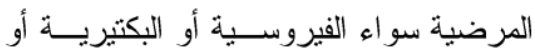

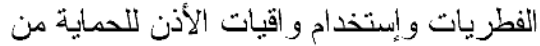

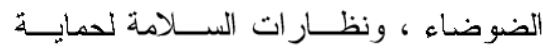
العينين من الاشعة أو انبعاثــات و الأبخـــة الفة الكيماوية، وقفاز ات وملابس خاصة للوقايسـة من التلوث المباشر، وغرف خاصة لتبــيل ملابس العمل و الاستحمام قبل المغادرة منعاً لانتقال التلوث الي العائلة و المنزل، و إجـــــاء فحوص طبية دورية للعمال للكثف المبكـر

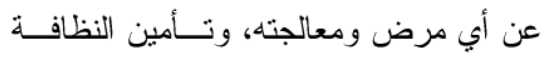
و التهوية للحماية من أخطار العوامل الحيوية

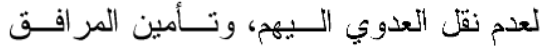
الصحية ومياه الثرب النقية ودور ات الميــاه وغرف الطعام الآمنة. وقد ظل السلوك الفردي ســلبياً نجـــاه بيئــة العمل لاسباب ترتبط بمستوب التعليم و النقافة

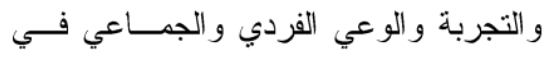
أو ساط العاملين. ويقتصر الحديث عموما في هذا البحث علي الماطي

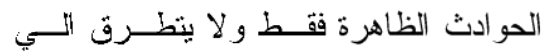
الأمر اض المهنية و الثأثير ات "الخفية" الطويلة الأجل فالإصابات و الحو ادث المنظورة يمكن 


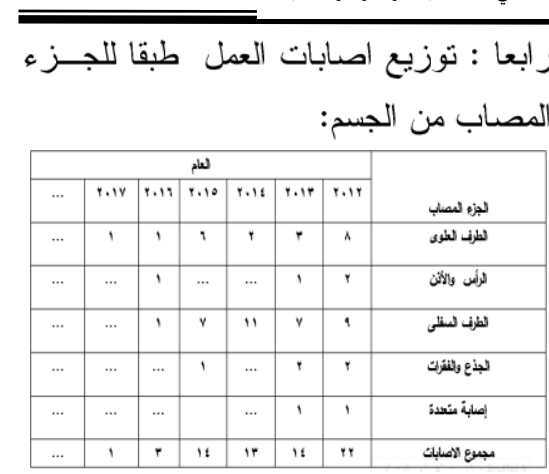

خامسا : توزيــع الاصــابات طبقـــآلآتـار

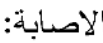

\begin{tabular}{|c|c|c|c|c|c|c|}
\hline \multicolumn{6}{|c|}{ بحميو الاصلبك } & \multirow[b]{2}{*}{ تتِجة الإصبلة } \\
\hline$r .1 \mathrm{~V}$ & 9.17 & r.10 & 9.18 & p.ir & rin & \\
\hline$\ldots$ & ... & ... & $\ldots$ & $\ldots$ & $\ldots$ & 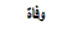 \\
\hline 1 & 1 & $\circ$ & ? & $r$ & 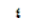 & عجز إصائي \\
\hline$\ldots$ & $r$ & 9 & 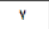 & $\pi r$ & $1 \mathrm{in}$ & شغنار \\
\hline 1 & $\%$ & 15 & i" & 15 & ir & |الإملى \\
\hline
\end{tabular}

هـ الاستنتاجات والنتائَج و التوصيات:

استتناجات الدراسة : الاستات

• لوحظ بشكل عام عدم وجــود ســـلات

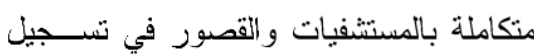
الاصـابات فقط و عدم وجود تســجيل دقيـق

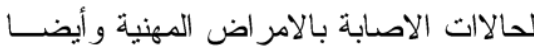

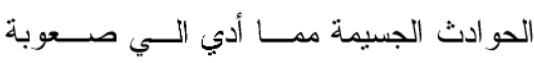

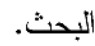

• وقعت معظم الاصـابات بسبب الانــزلاق مما يوضح سوء حالة الارضبات التي تمنث أسطح العمل. • معظم الاصـابات في العمال كانــث مـن نصيب ذوي التعليم المنخفض. • كما كانت نسبة الاصنابة الأكثر في الفئات

$$
\text { التعمرية الادني (عديمي الخبرة). }
$$

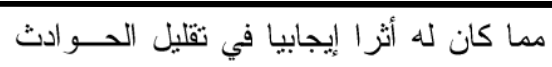

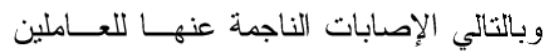
بهذه الأقسام و الذي تظهره نتائج الدراسة .

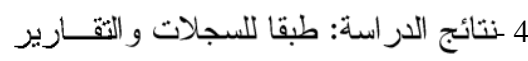

النصف سنوية لمسنتفي جامعة المنصورة

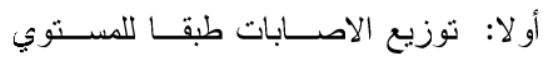

\begin{tabular}{|c|c|c|c|c|c|c|}
\hline \multicolumn{6}{|c|}{ للئ } & \multirow[b]{2}{*}{ لwind } \\
\hline 5.14 & 5.11 & 5.10 & T.16 & T.14 & ris & \\
\hline$=$ & 1 & - & 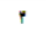 & $\mathfrak{i}$ & : & مهو أبنا| (بكلى \\
\hline$=$ & $=$ & 1 & r & 1 & 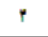 & أكله \\
\hline 1 & 1 & $r$ & $A$ & $A$ & 11 & شنهط \\
\hline$=$ & $=$ & 1 & $=$ & 1 & p & ترلئأجبعة: \\
\hline 1 & " & if & II & if & $\pi$ & الإبلى \\
\hline
\end{tabular}

ثانيا : نوزيع الاصابات طبقا للفئة العمرية :

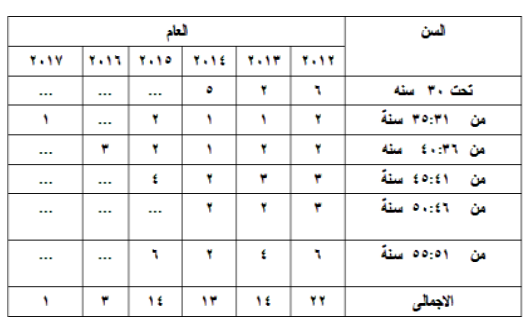

ثالثا: توزيع أعداد الاصابات حسب السبب

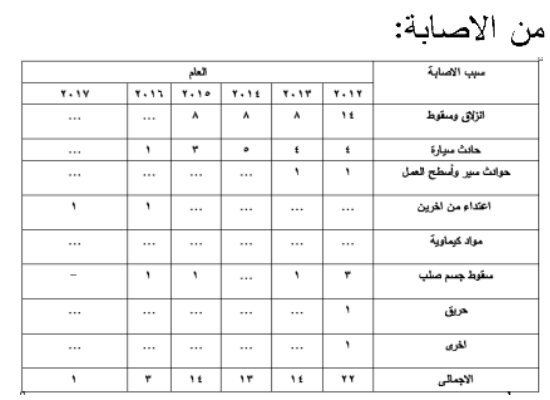


- وجود فروق بين العاملين الذين تعرضوا

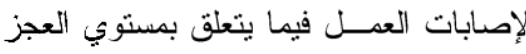

$$
\text { الحادث من الاصابة. }
$$

وجود فروق بين العاملين الـــنين تعرضــــوا

$$
\text { لإصابات العمل من حيث سبب الاصدابة. }
$$

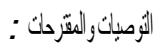

- إجر اء العديد من الدراسات الميدانية التهي

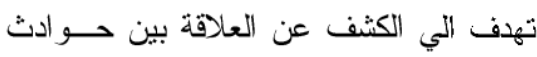

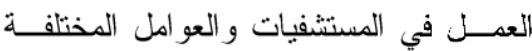
(شخصية أو بيئية محيطة) و العمل علي الحد أو النقلبل من إمكانيــة حدوثها.

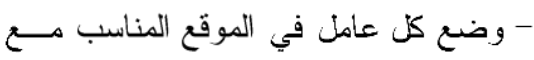

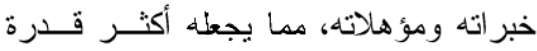
علي تفادي الأخطار الناتجة عن العمل الذي لئل يقوم به. - توفير فرصدة التـدريب الكاملــة لجميــع العاملين، مما بكسبهم الخبرة و المعرفة بكيفية

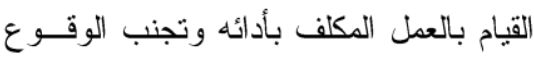

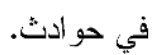

- امداد العامل بوسائل الحماية الثخصــية، و التأكيد علي ضرورة استعمانها. - التتبيه المستمر علي العساملين وتــدريبهر علي أخذ الحيطة والحذر عند القيام بتتفيــذ

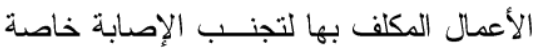

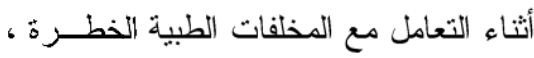

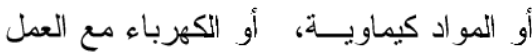

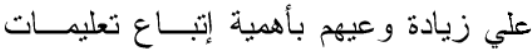

• معظم الاصـابات حدثت بسبب انــزلاقهم

وسقوطهم علـي الارض أوســقوط اجسـام عليهم أو الاصطدام او ملامسة أو إنســكاب

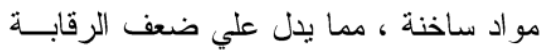
و وعدم الالتز ام بتعليمات السلامة.

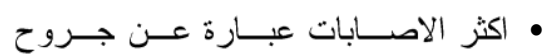

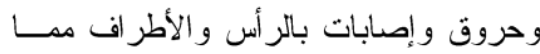
يدل علي عدم الالتزام بتعليمـات الســلامة بسبب عدم التوعي أو التعليم المنخفض.

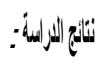
- ضرورة عمل حملات توعية صحية وفي لمال

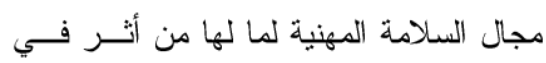

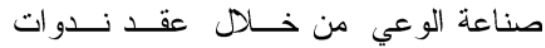

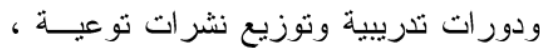

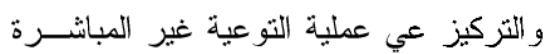

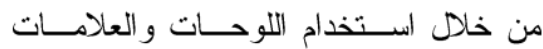
الارشادية في حملات التو عية بشكل مستمر . وقد نوصل الباحث التي النتائج التالية: - وجود فروق بين العاملين الذين تعرضــــوا لـالية لإصـابات العمل فيمـا يتعلق بمتغير السـن لئن (الفئة العمرية) - وجود فروق بين العاملين الذين تعرضــوا

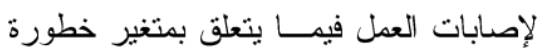
العمل . العن - وجود فروق بين العاملين الذين تعرضـــوا

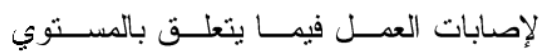

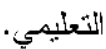




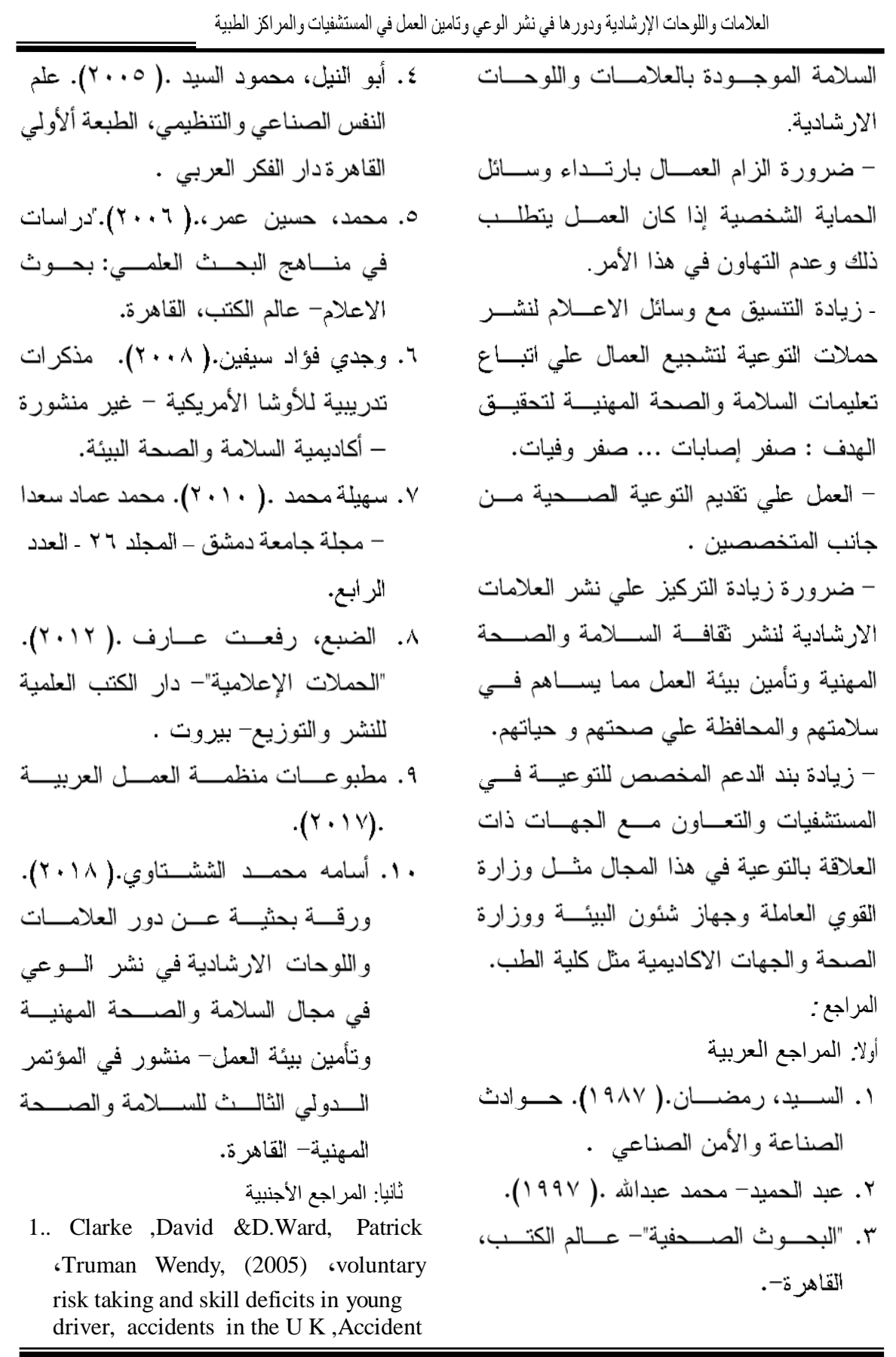


analysis and prevention, vol 37, no3,pp523- 529.

2. Laflame,Lucie(1997) ، Age- Related Injuries among Male and Female Assembly Workers: A Study int the Swedish Automobile Industry Sudish automobile industrielies, Industrialrelatione, 52,3,p608-619.

3. New OSHA/ANSI Safety Sign Systems FOR TODAY'S WORKPLACES2013.

4. Energy Institute, 2008. Guidance on effective workplace involvement in health and safety. energyinst.org/technical/humanandorganisationalfactors/ human-andorganisationalfactors workforceinvolvement (accessed 13 August 2013) 